OPEN ACCESS

Edited by:

Andrés Finzi,

Université de Montréal, Canada

Reviewed by:

Nicolas Chomont,

Université de Montréal, Canada

Matthew Parsons,

Emory University, United States

Catherine A. Blish,

Stanford University, United States

*Correspondence:

Michael D. Grant

mgrant@mun.ca

Specialty section:

This article was submitted to

Virus and Host

a section of the journa

Frontiers in Cellular and Infection

Microbiology

Received: 05 February 2020 Accepted: 02 April 2020

Published: 05 May 2020

Citation:

Holder KA and Grant MD (2020) TIG/T

Blockade: A Multipronged Approach

to Target the HIV Reservoir.

Front. Cell. Infect. Microbiol. 10:175.

doi: 10.3389/fcimb.2020.00175

\section{TIGIT Blockade: A Multipronged Approach to Target the HIV Reservoir}

\author{
Kayla A. Holder and Michael D. Grant ${ }^{*}$ \\ Immunology and Infectious Diseases Program, Division of BioMedical Sciences, Faculty of Medicine, Memorial University of \\ Newfoundland, St. John's, NL, Canada
}

During chronic human immunodeficiency virus type 1 (HIV-1) infection, upregulation of inhibitory molecules contributes to effector cell dysfunction and exhaustion. This, in combination with the ability of HIV-1 to reside dormant in cellular reservoirs and escape immune recognition, makes the pathway to HIV-1 cure particularly challenging. An idealized strategy to achieve HIV-1 cure proposes combined viral and immune activation by "shock"ing HIV-1 out of latency and into an immunologically visible state to be recognized and "kill"ed by immune effector cells. Here we outline the potential for blockade of the inhibitory immune checkpoint $T$ cell immunoreceptor with immunoglobulin and ITIM domains (TIGIT) to overcome natural killer (NK) cell and T cell inhibition associated with HIV-1 infection and invigorate antiviral effector cell responses against $\mathrm{HIV}-1$ reactivated from the latent cellular reservoir.

Keywords: HIV-1, TIGIT, PVR, checkpoint inhibitor, T cell, NK cell

\section{INTRODUCTION}

Combination antiretroviral therapy (cART) reduces human immunodeficiency virus type 1 (HIV-1) replication to levels where the amount of viral ribonucleic acid (RNA) in the bloodstream falls below current limits of detection. In most cases, maintenance of undetectable viral loads requires strict adherence to therapy (Chun et al., 1995, 1997; Finzi et al., 1999). Despite their efficacy, complete eradication of HIV-1 is unattainable with current cART regimes. During early infection, HIV-1 establishes proviral reservoirs, concealing itself within various cell types in different anatomical niches (Wong and Yukl, 2016; Baxter et al., 2018). In this largely dormant state, the HIV-1 reservoir is invisible to the immune system and insensitive to cART (Finzi et al., 1997). As a consequence of this widespread thorough concealment, if cART is interrupted, HIV-1 reactivates and produces replication-competent viruses capable of nascent infection (Wong et al., 1997; Finzi et al., 1999). Organs and tissues such as the gut and lymph nodes are key sites enriched for cells harboring HIV-1 provirus (Wong and Yukl, 2016). Although various types of cells including macrophages, monocytes and astrocytes can serve as HIV-1 reservoirs, the predominant cell type containing HIV-1 provirus are $\mathrm{CD}_{4}^{+} \mathrm{T}$ cells and, thus, they are the predominant source of viral replication with withdrawal of cART (Finzi et al., 1999; Wong et al., 2019). Seeding itself in long-lived memory $\mathrm{CD}^{+}{ }^{+} \mathrm{T}$ cells during acute and ongoing infection allows HIV-1 to persist indefinitely, despite consistent and effective cART suppression.

In the absence of cART, activation of the resting $\mathrm{CD} 4^{+} \mathrm{T}$ cells harboring HIV-1 provirus drives HIV-1 out from latency, replenishes the reservoir and promotes disease progression. Cure of the "Berlin patient" in 2008 and the "London patient" in 2019 with HIV-1-resistant bone marrow transplants provides proof of concept that HIV-1 can be eradicated in those already living with the virus (Hutter et al., 2009; Gupta et al., 2019). Although application of this approach is not feasible 
for the vast majority of people living with HIV-1 (PLWH), other elimination strategies are under investigation. These can include "block and lock" or gene editing, both of which aim to fix latent proviral HIV in a permanent inactive state with either drug therapy or in situ HIV genome editing. Conversely, a "kick/shock and kill" approach focuses on purging the latent HIV-1 reservoir by forced HIV activation from reservoir cells, thereby exposing it to the immune system and/or cART (Deeks, 2012; Shan et al., 2012; Qu et al., 2013; Ahlenstiel et al., 2015; Mousseau et al., 2015; Zhu et al., 2015; Karpinski et al., 2016; Margolis et al., 2016). To completely cure HIV-1 infection by this latter approach, two currently unattainable objectives must be met. Firstly, viral reactivation needs to occur in all latently infected cells bearing replication competent viral genomes. Secondly, those cells in which HIV-1 reactivates must be eliminated efficiently enough to prevent spread to uninfected cells. The second goal requires enhanced antiviral immune function, likely combined with novel pharmacologic strategies. Direct reservoir cytolysis by $\mathrm{T}$ cell and specific antibody-dependent NK cell mechanisms is a key element of this goal. Incomplete purging of the latent HIV-1 reservoir, although not an absolute cure, may be sufficient to reduce or even remove dependence upon cART for suppression of HIV replication and yield a functional cure for HIV-1 infection. In light of the role that the immune system will play, similarities between cancer and chronic viral infection imply that administration of checkpoint inhibitors can benefit immunebased HIV-1 cure and treatment strategies.

Like cancer, chronic viral infection often progresses to a stage where effector cell functions fundamental for its control are severely impaired (Wherry and Kurachi, 2015; Bi and Tian, 2017). Following activation, T cells upregulate inhibitory receptors such as CTLA- 4 and PD- 1 to limit T cell responses and prevent immune pathology arising from unregulated responses (Wherry and Kurachi, 2015). In settings of chronic infection with persistent microbial replication, $\mathrm{T}$ cell function is dysregulated by sustained high expression of these inhibitory checkpoint receptors (Attanasio and Wherry, 2016; Wykes and Lewin, 2018). Checkpoint inhibitors targeting different inhibitory receptors on immune cells or their corresponding ligands are transforming cancer therapy and many are relevant to immunotherapy for HIV-1 infection. We focused this review on the T cell immunoreceptor with immunoglobulin and ITIM domains (TIGIT) immune checkpoint receptor as expression of TIGIT, its competitors, and its ligands are broadly dysregulated on multiple cell types in HIV-1 infection. Furthermore, recent studies indicate that TIGIT negatively regulates both T cell and NK cell antiviral effector functions. We will discuss findings that suggest that this regulatory axis is an especially exploitable immune checkpoint in HIV-1 reservoir elimination strategies engaging antiviral effector cells.

\section{Differential TIGIT Expression on Immune Cells}

Most NK cells and multiple T cell subsets, including memory $\mathrm{T}$ cells, regulatory $\mathrm{T}$ cells and follicular helper $\mathrm{T}$ cells $\left(\mathrm{T}_{\mathrm{FH}}\right)$, express TIGIT (Boles et al., 2009; Stanietsky et al., 2009; Yu et al., 2009; Levin et al., 2011; Wang et al., 2015; Wu et al., 2016). After interaction with either of its ligands, poliovirus receptor (PVR or CD155 or Necl-5), or PVRL2 (CD112 or nectin-2), TIGIT inhibits activation of $\mathrm{T}$ cell or NK cell effector functions (Stanietsky et al., 2009; Yu et al., 2009; Stengel et al., 2012). TIGIT belongs to a larger family of nectin and nectinlike receptors that all recognize the same group of ligands (Chan et al., 2012; Pauken and Wherry, 2014). Like TIGIT, TACTILE (CD96), and PVR-related Ig domain (PVRIG or CD112R) bind PVR, and PVRL2, respectively, whereas DNAM-1 (CD226) is a costimulatory counter receptor that competes with both TIGIT and TACTILE for PVR engagement and with PVRIG for PVRL2 binding (Figure 1) (Anderson et al., 2016; Zhu et al., 2016; Dougall et al., 2017; Xu et al., 2017; Sanchez-Correa et al., 2019). The inhibitory receptor PVRIG is expressed on activated $\mathrm{T}$ cells and NK cells (Figure 1), however, there is a lack of conclusive evidence in human NK cell studies as to whether TACTILE negatively or positively regulates activation (Fuchs et al., 2004; Georgiev et al., 2018; Whelan et al., 2019). Although PVR is a common ligand for TIGIT, TACTILE, and DNAM-1, the binding affinities vastly differ, with TIGIT having a greater affinity for PVR than either DNAM-1 or TACTILE (Figure 1) (Yu et al., 2009). This domination TIGIT has over DNAM-1 for ligand binding favors effector cell inhibition over effector cell costimulation, thereby dampening immune responses. Another means by which TIGIT controls T cell or NK cell activation is by interfering with DNAM-1 homodimerization by forming a heterodimer with DNAM-1 in cis (Figure 1) (Johnston et al., 2014). The intracellular TIGIT/DNAM-1 complex prevents effective intercellular DNAM-1/ligand interactions and reduces effector cell costimulation. This family of paired receptors and ligands constitute a regulatory signaling pathway resembling that of CD28 and CTLA- 4 with antagonistic effects conveyed through differential receptor binding of the same ligand (Martinet and Smyth, 2015).

One hallmark of chronic HIV-1 infection is disruption of normal lymphocyte functions, leading to signs and symptoms of immune exhaustion. This exhaustion profile is illustrated by increased expression of multiple inhibitory immune checkpoint molecules including PD-1, CTLA-4, TIM-3, and LAG-3 on $\mathrm{CD}^{+} \mathrm{T}$ cells and in some instances, on NK cells (Wherry et al., 2007; Anderson et al., 2016). In contrast to these wellcharacterized exhaustion markers, TIGIT is found to varying extents on NK cells and naïve $\mathrm{CD}^{+} \mathrm{T}$ cells and is further upregulated after activation (Yu et al., 2009). There is convincing evidence of a central role for TIGIT in control of $\mathrm{CD} 8^{+}$ $\mathrm{T}$ cell maturation and exhaustion (Johnston et al., 2014). However, considering its parallel regulation of NK cell functions, targeting TIGIT with checkpoint inhibitors may have even greater implications for bolstering antiviral immunity than targeting PD-1 or CTLA-4. Of all lymphocyte subsets, NK cells have the highest fraction of cells constitutively expressing TIGIT receptors (Wang et al., 2015). Between 20 and 90\% of resting NK cells express TIGIT and levels are increased by acute and chronic viral infections or cancers (Bi et al., 2014; Johnston et al., 2014; Wang et al., 2015; Zhang et al., 2018). 


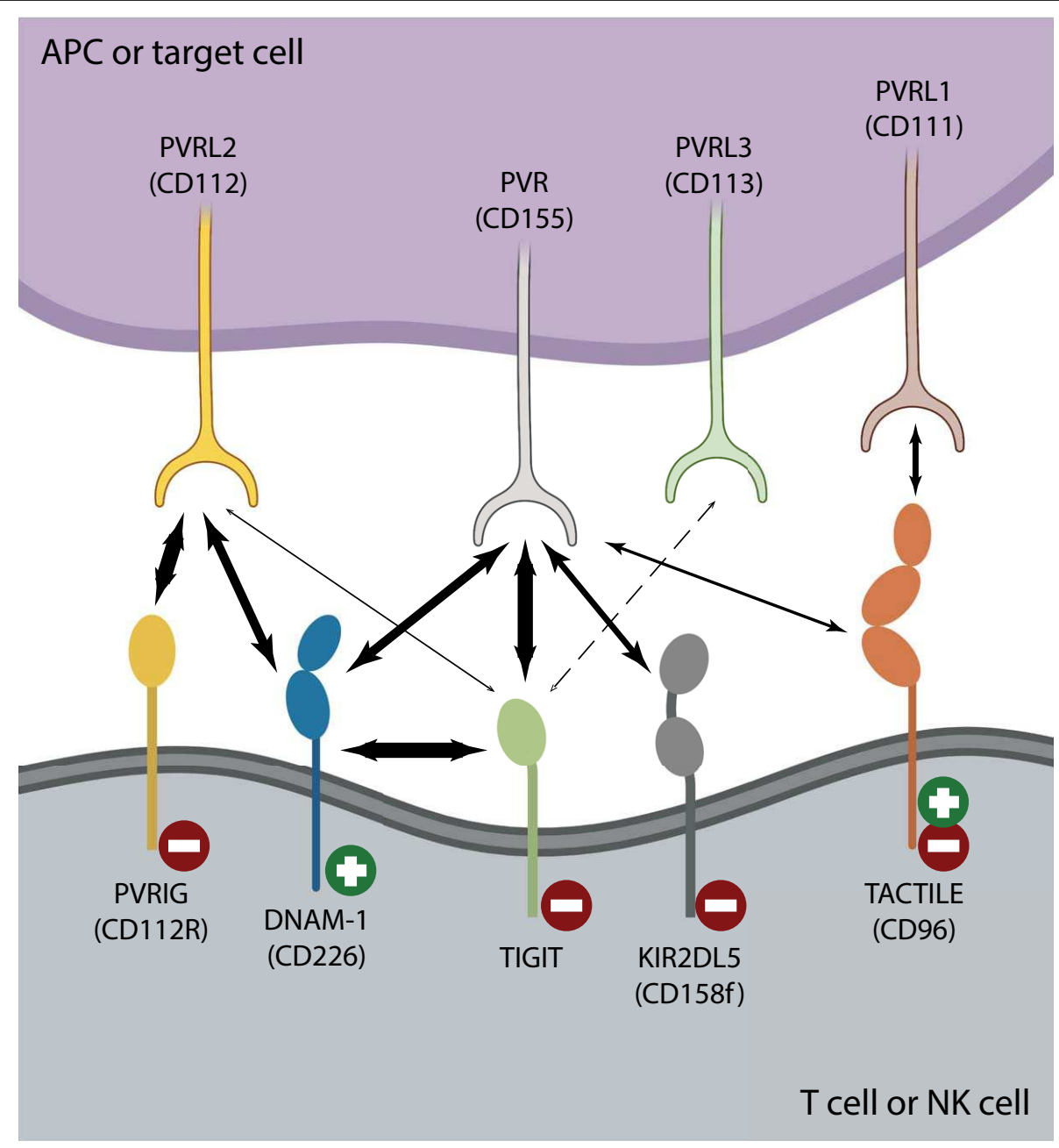

FIGURE 1 | The TIGIT/DNAM-1 immune checkpoint axis. Interactions between inhibiting $(\boldsymbol{\theta})$ and activating $(\boldsymbol{\oplus})$ T cell or NK cell receptors belonging to the nectin or nectin-like family of receptors and their corresponding family of ligands are depicted. Strong interactions such as those between TIGIT and PVR or DNAM-1 in cis or PVRIG and PVRL2 are illustrated with heavy arrows. There is no clear consensus regarding whether TIGIT binds PVRL3 (dotted arrow) and it is unclear whether TIGIT/PVRL2 interactions are physiologically relevant in vivo (Stanietsky et al., 2009; Yu et al., 2009; Whelan et al., 2019). DNAM-1 interacts with both PVR and PVRL2 to counter inhibition, yet does so with lower affinity than either TIGIT or PVRIG. TACTILE preferentially interacts with PVRL1 over PVR (Holmes et al., 2019). The affinity of KIR2DL5 for PVR binding is currently unknown, as is whether any other nectin or nectin-like ligand or receptor can serve as its binding partner.

Targeting TIGIT is an especially attractive approach to incorporate into HIV-1 cure strategies as it impacts multiple functions of multiple types of effector cells. Its widespread expression on $\mathrm{NK}$ cells and $\mathrm{CD}^{+}{ }^{+} \mathrm{T}$ cells enhances the likelihood of TIGIT blockade having a meaningful impact in the setting of chronic infection. In this setting, $\mathrm{CD} 8^{+} \mathrm{T}$ cells acquire expression of inhibitory receptors, including TIGIT, all contributing to maintenance of an immune exhausted state. Utilizing therapeutic monoclonal antibodies $(\mathrm{mAb})$ to release the brakes on exhausted $\mathrm{CD}^{+} \mathrm{T}$ cells and on NK cells expressing high amounts of TIGIT can counter inhibition to favor restoration of productive antiviral effector functions.

\section{TIGIT Regulates Effector Cells in HIV-1} Infection

Expression of TIGIT is broadly dysregulated on both $\mathrm{CD}^{+} \mathrm{T}$ cells and NK cells in HIV-1 infection. An increased fraction of $\mathrm{CD}^{+} \mathrm{T}$ cells expressing TIGIT arises despite early initiation of effective cART (Chew et al., 2016; Tauriainen et al., 2017). The high potential impact of targeting TIGIT as a therapeutic strategy to invigorate effector cell responses against HIV-1 is emphasized by TIGIT expression on more than half of $\mathrm{CD}^{+} \mathrm{T}$ cells and almost all HIV-1-specific $\mathrm{CD}^{+} \mathrm{T}$ cells in PLWH (Chew et al., 2016; Tauriainen et al., 2017). Cells expressing TIGIT proliferated less and mounted weaker antiviral cytokine responses compared with their $\mathrm{TIGIT}^{\text {neg }} \mathrm{CD}^{+} \mathrm{T}$ 
cell counterparts, indicating a prominent role for TIGIT as a negative regulator of $\mathrm{HIV}-1$-specific $\mathrm{CD}^{+} \mathrm{T}$ cell immunity (Chew et al., 2016). Additionally, TIGIT ${ }^{\text {pos }} \mathrm{CD}^{+} \mathrm{T}$ cells from PLWH have increased PD-1 co-expression, which correlates with HIV-1 disease progression (Chew et al., 2016). ADDIN EN.CITE (Cella et al., 2010; Tauriainen et al., 2017; Yin et al., 2018) Interrupting TIGIT signaling using therapeutic mAb blockade rescues $\mathrm{CD}^{+} \mathrm{T}$ cell antiviral activity. If signaling through either TIGIT or PD-1 receptors is prevented by $\mathrm{mAb}, \mathrm{CD}^{+} \mathrm{T}$ cell interferon (IFN) $-\gamma$ responses and cytotoxicity increase (Johnston et al., 2014; Chew et al., 2016). However, IL-2 production and $\mathrm{T}$ cell proliferation is reestablished only when blockade of both receptors is imposed (Figure 2A) (Johnston et al., 2014; Chew et al., 2016). In parallel with increased TIGIT on $\mathrm{CD}^{+} \mathrm{T}$ cells, its costimulatory counterpart, DNAM-1, is often downregulated, further contributing to $\mathrm{T}$ cell exhaustion (Cella et al., 2010; Tauriainen et al., 2017). This "one-two punch" increases inhibitory intercellular TIGIT/PVR interactions and cis TIGIT/DNAM-1 heterodimers further restrict the potential for productive costimulation mediated by DNAM1/PVR interactions (Figure 1).

Similar to the relationship seen with $\mathrm{CD}^{+} \mathrm{T}$ cells, higher levels of TIGIT on NK cells correlate with HIV-1 disease progression (Yin et al., 2018). Although TIGIT blockade can rescue NK cell function against cancer, further evidence illustrating the potential benefits of targeting the TIGIT axis in the context of HIV-1 infection is needed (Zhang et al., 2018). While TIGIT expression is increased on NK cells from treatment naïve PLWH, cART may return TIGIT expression to similar levels as that of healthy controls (Yin et al., 2018; Vendrame et al., 2020). In untreated PLWH, NK cells expressing higher amounts of TIGIT were less likely to degranulate and produce IFN- $\gamma$ in response to cytokine stimuli than those that did not express TIGIT. In this case, baseline NK cell function was rescued by $\mathrm{mAb}$ against TIGIT (Yin et al., 2018). In another study in which NK cells were activated for 3 days with IL-2, blockade of TIGIT provided no benefits to NK cells responding against in vitro HIV1 infected autologous primary $\mathrm{CD}^{+} \mathrm{T}$ cells (Vendrame et al., 2020). In the setting of active HIV-1 infection, TIGIT expression is increased on subsets of NK cells coexpressing DNAM-1 (Yin et al., 2018; Vendrame et al., 2020). Combining viral reactivation strategies with effector cell reinvigoration by preventing TIGIT interactions with either its ligand or DNAM-1 should promote cytolysis of infected cells (Figure 2B). More evidence is needed to delineate the cytotoxic potential of these cells. Expression of TIGIT on CD8 ${ }^{+}$T cells and NK cells suggests that TIGIT-specific $\mathrm{mAb}$ therapy could synergistically unleash both types of antiviral effector cells to more robustly target active HIV-1 infection.

\section{A Ligand for TIGIT Is Enriched on HIV-1 Reservoir Cells}

Although expression levels of many inhibitory checkpoint molecules increase on multiple types of effector cells during HIV1 infection, inhibition relies on the interactions between these receptors, and their cognate ligands. The predominant ligand for TIGIT and DNAM-1 is PVR, which is expressed on monocytes, dendritic cells, $\mathrm{T}$ cells and other cell types including tumor cells and HIV-1-infected cells (Mendelsohn et al., 1989; Pende et al., 2006; Chauvin et al., 2015; Chew et al., 2016). Originally identified in 1989 as a receptor for poliovirus, PVR belongs to a larger family of molecules that facilitate cell adhesion and migration, while over-expression of PVR in transformed cells promotes proliferation (Mendelsohn et al., 1989; Takai et al., 2008). Stimulated T cells have increased total PVR protein and cell surface expression levels, with preferential PVR expression on proliferating $T$ cells in the $S$ or $G_{2} / M$ cell cycle phase (Ardolino et al., 2011). Increased cellular PVR expression occurs after the DNA damage response (DDR) pathway is induced (Ardolino et al., 2011). Although activated primary CD4 ${ }^{+} \mathrm{T}$ cells express PVR, whether or not HIV-1 influences PVR expression on circulating primary $\mathrm{CD}^{+} \mathrm{T}$ cells remains controversial (Davis et al., 2017).

During infection, expression of HIV-1-encoded Vpr helps promote cell cycle arrest in $\mathrm{G}_{2}$ via the DDR pathway (Andersen et al., 2008). Through this same Vpr-dependent mechanism, PVR was reported to be upregulated on the surface of HIV-1infected Jurkat T cells, yet expression of Nef and/or Vpu reduced surface-expressed PVR on both Jurkat and primary CD4 ${ }^{+} \mathrm{T}$ cells (Matusali et al., 2012; Vassena et al., 2013; Bolduan et al., 2014). Another study reported no role for HIV-1-specific modulation of PVR expression on primary CD4 ${ }^{+} \mathrm{T}$ cells (Davis et al., 2017). These studies used various in vitro systems with $\mathrm{CD} 4^{+} \mathrm{T}$ cell lines or ex vivo $\mathrm{CD}^{+} \mathrm{T}$ cells from healthy controls infected with different laboratory passaged HIV-1 strains. In all cases, PVR expression was assessed on all infected $\mathrm{T}$ cells, yet in vitroinfected $\mathrm{CD}^{+} \mathrm{T}$ cells can be subsequently distinctly grouped into either $\mathrm{CD} 4^{\text {pos }}$ or $\mathrm{CD} 4^{\text {neg }}$ cells (Tremblay-McLean et al., 2017). In so doing, Tremblay-McLean et al. found that surface PVR expression is reduced on infected CD $4^{\text {neg }} \mathrm{T}$ cells compared with infected CD4 ${ }^{\text {pos }}$ T cells (Tremblay-McLean et al., 2017). This could indicate that if HIV-1 does regulate PVR expression in vivo, productively infected or reservoir $\mathrm{T}_{\mathrm{FH}}$ cells that maintain their expression of CD4 may have a different PVR expression profile than their $\mathrm{CD} 4^{\text {neg }} \mathrm{T}$ cell counterparts.

Investigation of ex vivo PVR expression on $\mathrm{CD}^{+} \mathrm{T}$ cells from PLWH has been limited. Very low levels of PVR expression on circulating $\mathrm{CD}^{+} \mathrm{T}$ cells combined with the relative inaccessibility of lymph node sections from PLWH make informed assessment of PVR expression problematic (Yin et al., 2018; Vendrame et al., 2020). Upregulation of PVR can occur on $\mathrm{CD}^{+}{ }^{+} \mathrm{T}$ cells in HIV-1 infection, especially on lymph node $\mathrm{T}_{\mathrm{FH}} \mathrm{CD}^{+} \mathrm{T}$ cells, which are the major site of HIV-1 reservoir concentration (Perreau et al., 2013; Banga et al., 2016; Tauriainen et al., 2017). Further, within the lymph nodes from PLWH, PVR is expressed on both germinal center $\mathrm{CD}^{+}$cells and interdigitating follicular DCs (Cella et al., 2010). This compact compartment comprised of cells expressing PVR in proximity to $\mathrm{CD}^{+}{ }^{+} \mathrm{T}$ cells enriched in HIV-1 provirus could exploit higher localized TIGIT expression on $\mathrm{CD}^{+} \mathrm{T}$ cells and NK cells to limit effector cell functions as they transit through lymph nodes. As $\mathrm{NK}$ cell and $\mathrm{CD}^{+} \mathrm{T}$ cell expression of TIGIT increases with acute HIV-1 infection, introducing mAb therapy to overcome the higher affinity TIGIT/PVR inhibitory interaction in favor of DNAM-1/PVR-mediated activation is a rational strategy to address lingering HIV-1 infection (Yin et al., 2018). In this event, PVR expressed on reservoir $\mathrm{CD}^{+}{ }^{+} \mathrm{T}$ cells would render them 


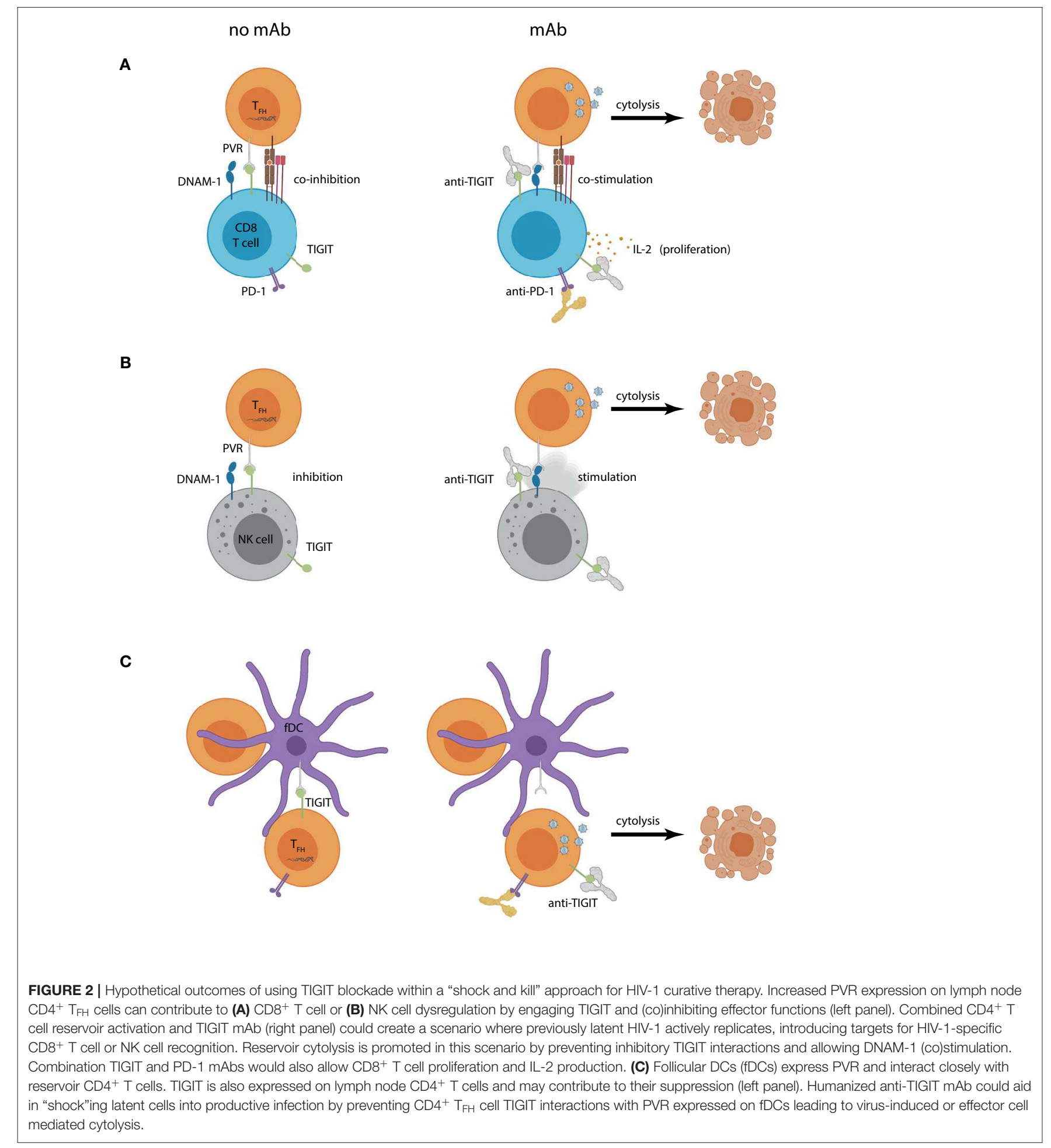

more susceptible targets for DNAM-1-expressing $\mathrm{CD}^{+} \mathrm{T}$ cells and NK cells (Figures $2 \mathrm{~A}, \mathbf{B}$ ).

In 2019, killer cell immunoglobulin-like receptor (KIR)2DL5, an inhibitory receptor expressed on NK cells and $\mathrm{CD} 8^{+} \mathrm{T}$ cells, was identified as a binding partner for PVR, adding another facet to this already complex regulatory pathway (Estefania et al., 2007;
Husain et al., 2019). The genes encoding KIR2DL5 (KIR2DL5A and KIR2DL5) are highly polymorphic (Vilches et al., 2000a,b). Less than $10 \%$ of CD56 dim NK cells and a very small fraction of the $\mathrm{CD} 8^{+} \mathrm{T}$ cells of carriers express the most common allele, $2 D L 5 A^{*} 001$, which is detectable by mAb UP-R1 (Estefania et al., 2007; Cisneros et al., 2012). An accurate measure of KIR2DL5 
prevalence in the wider population is currently unavailable as it is unknown whether this is the only allele expressed or whether polymorphisms arising in other alleles alter epitopes recognized by UP-R1 (Cisneros et al., 2012, 2016). While multiple factors suggest that inhibiting TIGIT/PVR interactions is a suitable strategy to invigorate effector cell responses against HIV-1, PLWH expressing KIR2DL5 may be less likely to benefit from this approach. Studies are needed to determine the antiviral effector potential of NK cells expressing KIR2DL5 and whether they co-express other nectin or nectin-like receptors.

\section{TIGIT Is Expressed on HIV-1 Reservoir Cells}

A significant hurdle to achieving HIV-1 cure is the lack of HIV1 antigen expression on reservoir $\mathrm{CD} 4{ }^{+} \mathrm{T}$ cells, which leaves no appropriate means to target them immunologically. Without specific cell surface markers or HIV-1 antigen expression/peptide presentation to identify HIV-1-infected cells, no level of competent effector cell function can eradicate HIV. Selectively targeting latently infected cells that comprise the HIV-1 reservoir is a subsidiary approach to HIV-1 cure. Together with $\mathrm{CD}^{+} \mathrm{T}$ cells and NK cells, $\mathrm{CD}^{+}{ }^{+} \mathrm{T}$ cells, including $\mathrm{T}_{\mathrm{FH}}$ cells residing deep within lymph node tissues, express TIGIT (Yu et al., 2009; $\mathrm{Wu}$ et al., 2016). The $\mathrm{CD}^{+} \mathrm{T}$ cell fraction expressing TIGIT is enriched for integrated HIV-1 DNA and the frequency of TIGITpos cells that also co-express PD-1 and LAG-3 correlates with the size of the HIV-1 reservoir (Fromentin et al., 2016). Expression of TIGIT on CD4 ${ }^{+} \mathrm{T}$ cells, alone or in combination with other immune checkpoint receptors identifies a subset of $\mathrm{CD}^{+}{ }^{+} \mathrm{T}$ cells more likely to harbor latent HIV-1.

Although TIGIT expression can help identify HIV-1 reservoirs, these cells need to be activated or shocked into productive infection to express HIV-1 antigens or associated stress proteins enabling recognition by antiviral effector cells. Maintenance of stable HIV-1 reservoirs involves persistent inhibition through interactions between checkpoint inhibitors, such as PD-1 or TIGIT, and their ligands (Wykes and Lewin, 2018). Consistent with the latency reversal noted with antiPD-1 mAb, introducing anti-TIGIT mAb to unleash negative regulation can help shock TIGIT-expressing $\mathrm{CD}^{+} \mathrm{T}$ cells into activation and shift latent HIV-1 into active production (Figure 2C) (Chew et al., 2016; Fromentin et al., 2016, 2019; Evans et al., 2018; Guihot et al., 2018; Wykes and Lewin, 2018). Targeting TIGIT as part of a cure strategy for HIV-1 could concurrently help force HIV-1 out of hiding, while rescuing $\mathrm{CD}^{+} \mathrm{T}$ cell and NK cell antiviral functions to bridge effector cell functions with recognition of HIV-1-infected cells-a multipronged "shock and kill" approach.

\section{CONCLUSION}

We have discussed findings that suggest TIGIT inhibition of $\mathrm{CD}^{+}{ }^{+} \mathrm{T}$ cell and NK cell surveillance against HIV-1-infected $\mathrm{CD}^{+}{ }^{+} \mathrm{T}$ cells and monocytes, compounded by dysregulation of PVR and DNAM-1 expression, constitutes an exploitable immune checkpoint in HIV-1 reservoir elimination strategies engaging antiviral effector cells. The reasons that TIGIT could be an especially attractive target are several fold. Most importantly, TIGIT is expressed on most NK cells and almost all HIV-specific CD8 $^{+}$T cells in PLWH (Wang et al., 2015; Tauriainen et al., 2017; Yin et al., 2018). While this may favor targeting TIGIT over other inhibitory receptors such as PD-1 or CTLA-4, there is a case for using combinations of checkpoint inhibitors. For example, blocking TIGIT increased degranulation, IFN- $\gamma$ production and proliferation of antiviral effectors, however, blockade of both TIGIT and PD-1 rescued IL-2 production, an important correlate of immune stability in PLWH (Johnston et al., 2014; Chew et al., 2016). In some settings, TIGIT blockade increases NK cell natural degranulation and antiviral cytokine release and likewise enhances cytokine release by $\mathrm{CD} 8^{+}$and $\mathrm{CD}^{+} \mathrm{T}$ cells and degranulation of HIV-specific $\mathrm{CD}^{+} \mathrm{T}$ cells (Chew et al., 2016; Fromentin et al., 2016; Tauriainen et al., 2017; Yin et al., 2018). Secondly, there is evidence that HIV-1 infection of $\mathrm{CD}^{+}$ $\mathrm{T}$ cells induces upregulation of PVR expression and that the latent HIV reservoir is to some extent concentrated in $\mathrm{CD} 4^{+} \mathrm{T}$ cells expressing PVR and/or TIGIT (Cella et al., 2010; Tauriainen et al., 2017; Yin et al., 2018). Thus, at least a fraction of the CD4 ${ }^{+}$ $\mathrm{T}$ cells activated for nascent HIV-1 replication is pre-armed to inhibit antiviral effector cell function through PVR engagement of TIGIT. Previous studies indicating that endogenous HIVspecific $\mathrm{CD}^{+} \mathrm{T}$ cell responses of PLWH are insufficient to address nascent HIV-1 reactivation underscore the necessity to enhance antiviral effector functions in concert with HIV-1 reactivation (Shan et al., 2012).

The breadth of its effects on T cells and NK cells as well as specificity for cells in which the HIV-1 reservoir is concentrated combine to highlight the potential of TIGIT blockade in immunotherapeutic HIV-1 cure strategies. Several humanized anti-TIGIT mAb (AB154 and Etigilimab) have already entered clinical trials in cancer therapy, alone and in combination with anti-PD-1. These early stage studies indicate a favorable safety profile with effective TIGIT blockade. Experience in the cancer setting should help inform strategies for TIGIT blockade in PLWH, including whether better outcomes can be achieved when used in combination with other checkpoint inhibitors. For cure strategies that involve widespread reactivation of HIV replication and purging of the exposed infected cells, it will be critical to determine which effector cells or functions can most rapidly be brought to bear against nascent HIV-1 replication.

\section{AUTHOR CONTRIBUTIONS}

$\mathrm{KH}$ and $\mathrm{MG}$ jointly wrote and edited the manuscript.

\section{FUNDING}

Research in the area addressed by this review was supported by a research operating grant from the Canadian Institutes of Health Research (CIHR) PJT 361426 awarded to MG. KH was supported by a CIHR CGS-D fellowship.

\section{ACKNOWLEDGMENTS}

Figures were created using BioRender and Adobe Illustrator. 


\section{REFERENCES}

Ahlenstiel, C., Mendez, C., Lim, S. T., Marks, K., Turville, S., Cooper, D. A., et al. (2015). Novel RNA duplex locks HIV-1 in a latent state via chromatin-mediated transcriptional silencing. Mol. Ther. Nucleic Acids 4:e261. doi: $10.1038 / \mathrm{mtna} .2015 .31$

Andersen, J. L., Le Rouzic, E., and Planelles, V. (2008). HIV-1 Vpr: mechanisms of G2 arrest and apoptosis. Exp. Mol. Pathol. 85, 2-10. doi: 10.1016/j.yexmp.2008.03.015

Anderson, A. C., Joller, N., and Kuchroo, V. K. (2016). Lag-3, Tim3, and TIGIT: co-inhibitory receptors with specialized functions in immune regulation. Immunity 44, 989-1004. doi: 10.1016/j.immuni.2016. 05.001

Ardolino, M., Zingoni, A., Cerboni, C., Cecere, F., Soriani, A., Iannitto, M. L., et al. (2011). DNAM-1 ligand expression on Ag-stimulated $\mathrm{T}$ lymphocytes is mediated by ROS-dependent activation of DNA-damage response: relevance for NK-T cell interaction. Blood 117, 4778-4786. doi: 10.1182/blood-2010-08-30 0954

Attanasio, J., and Wherry, E. J. (2016). Costimulatory and coinhibitory receptor pathways in infectious disease. Immunity 44, 1052-1068. doi: 10.1016/j.immuni.2016. 04.022

Banga, R., Procopio, F. A., Noto, A., Pollakis, G., Cavassini, M., Ohmiti, K., et al. (2016). PD-1(+) and follicular helper $\mathrm{T}$ cells are responsible for persistent HIV-1 transcription in treated aviremic individuals. Nat. Med. 22, 754-761. doi: $10.1038 / \mathrm{nm} .4113$

Baxter, A. E., O'Doherty, U., and Kaufmann, D. E. (2018). Beyond the replication-competent HIV reservoir: transcription and translationcompetent reservoirs. Retrovirology 15:18. doi: 10.1186/s12977-018-0 392-7

Bi, J., and Tian, Z. (2017). NK cell exhaustion. Front. Immunol. 8:760. doi: 10.3389/fimmu.2017.00760

Bi, J., Zhang, Q., Liang, D., Xiong, L., Wei, H., Sun, R., et al. (2014). T-cell Ig and ITIM domain regulates natural killer cell activation in murine acute viral hepatitis. Hepatology 59, 1715-1725. doi: 10.1002/hep.2 6968

Bolduan, S., Reif, T., Schindler, M., and Schubert, U. (2014). HIV-1 Vpu mediated downregulation of $\mathrm{CD} 155$ requires alanine residues 10, 14 and 18 of the transmembrane domain. Virology 464-465, 375-384. doi: $10.1016 /$ j.virol.2014.07.034

Boles, K. S., Vermi, W., Facchetti, F., Fuchs, A., Wilson, T. J., Diacovo, T. G., et al. (2009). A novel molecular interaction for the adhesion of follicular CD4 T cells to follicular DC. Eur. J. Immunol. 39, 695-703. doi: 10.1002/eji.2008 39116

Cella, M., Presti, R., Vermi, W., Lavender, K., Turnbull, E., OchsenbauerJambor, C., et al. (2010). Colonna and N. C. f. H. Immunology, A. V. Loss of DNAM-1 contributes to CD8+ T-cell exhaustion in chronic HIV-1 infection. Eur. J. Immunol. 40, 949-954. doi: 10.1002/eji.2009 40234

Chan, C. J., Andrews, D. M., and Smyth, M. J. (2012). Receptors that interact with nectin and nectin-like proteins in the immunosurveillance and immunotherapy of cancer. Curr. Opin. Immunol. 24, 246-251. doi: 10.1016/j.coi.2012.0 1.009

Chauvin, J. M., Pagliano, O., Fourcade, J., Sun, Z., Wang, H., Sander, C., et al. (2015). TIGIT and PD-1 impair tumor antigen-specific CD8(+) T cells in melanoma patients. J. Clin. Invest. 125, 2046-2058. doi: 10.1172/JCI 80445

Chew, G. M., Fujita, T., Webb, G. M., Burwitz, B. J., Wu, H. L., Reed, J. S., et al. (2016). TIGIT marks exhausted $\mathrm{T}$ cells, correlates with disease progression, and serves as a target for immune restoration in HIV and SIV infection. PLoS Pathog. 12:e1005349. doi: 10.1371/journal.ppat.10 05349

Chun, T. W., Carruth, L., Finzi, D., Shen, X., DiGiuseppe, J. A., Taylor, H., et al. (1997). Quantification of latent tissue reservoirs and total body viral load in HIV-1 infection. Nature 387, 183-188. doi: 10.1038/387 $183 \mathrm{a} 0$
Chun, T. W., Finzi, D., Margolick, J., Chadwick, K., Schwartz, D., and Siliciano, R. F. (1995). In vivo fate of HIV-1-infected T cells: quantitative analysis of the transition to stable latency. Nat. Med. 1, 1284-1290. doi: 10.1038/nm1295-1284

Cisneros, E., Estefania, E., and Vilches, C. (2016). Allelic polymorphism determines surface expression or intracellular retention of the human NK cell receptor KIR2DL5A (CD158f). Front. Immunol. 7:698. doi: 10.3389/fimmu.2016.00698

Cisneros, E., Moraru, M., N., Gomez-Lozano, M., Lopez-Botet, and Vilches, C. (2012). KIR2DL5: an orphan inhibitory receptor displaying complex patterns of polymorphism and expression. Front. Immunol. 3:289. doi: 10.3389/fimmu.2012.00289

Davis, Z. B., Sowrirajan, B., Cogswell, A., Ward, J. P., Planelles, V., and Barker, E. (2017). CD155 on HIV-infected cells is not modulated by HIV-1 Vpu and Nef but synergizes with NKG2D ligands to trigger NK cell lysis of autologous primary HIV-infected cells. AIDS Res. Hum. Retroviruses 33, 93-100. doi: 10.1089/AID.2015.0375

Deeks, S. G. (2012). HIV: Shock and kill. Nature 487, 439-440. doi: $10.1038 / 487439 a$

Dougall, W. C., Kurtulus, S., Smyth, M. J., and Anderson, A. C. (2017). TIGIT and CD96: new checkpoint receptor targets for cancer immunotherapy. Immunol. Rev. 276, 112-120. doi: 10.1111/imr.12518

Estefania, E., Flores, R., Gomez-Lozano, N., Aguilar, H., Lopez-Botet, M., and Vilches, C. (2007). Human KIR2DL5 is an inhibitory receptor expressed on the surface of NK and T lymphocyte subsets. J. Immunol. 178, 4402-4410. doi: 10.4049/jimmunol.178.7.4402

Evans, V. A., van der Sluis, R. M., Solomon, A., Dantanarayana, A., McNeil, C., Garsia, R., et al. (2018). Programmed cell death-1 contributes to the establishment and maintenance of HIV-1 latency. AIDS 32, 1491-1497. doi: 10.1097/QAD.0000000000001849

Finzi, D., Blankson, J., Siliciano, J. D., Margolick, J. B., Chadwick, K., Pierson, T., et al. (1999). Latent infection of CD4+ T cells provides a mechanism for lifelong persistence of HIV-1, even in patients on effective combination therapy. Nat. Med. 5, 512-517. doi: 10.1038/8394

Finzi, D., Hermankova, M., Pierson, T., Carruth, L. M., Buck, C., Chaisson, R. E., et al. (1997). Identification of a reservoir for HIV-1 in patients on highly active antiretroviral therapy. Science 278, 1295-1300. doi: 10.1126/science.278.5341.1295

Fromentin, R., Bakeman, W., Lawani, M. B., Khoury, G., Hartogensis, W., DaFonseca, S., et al. (2016). CD4+ T cells expressing PD-1, TIGIT and LAG-3 contribute to HIV persistence during ART. PLoS Pathog. 12:e1005761. doi: 10.1371/journal.ppat.1005761

Fromentin, R., DaFonseca, S., Costiniuk, C. T., El-Far, M., Procopio, F. A., Hecht, F. M., et al. (2019). PD-1 blockade potentiates HIV latency reversal ex vivo in CD4(+) T cells from ART-suppressed individuals. Nat. Commun. 10:814. doi: 10.1038/s41467-019-08798-7

Fuchs, A., Cella, M., Giurisato, E., Shaw, A. S., and Colonna, M. (2004). Cutting edge: CD96 (tactile) promotes NK cell-target cell adhesion by interacting with the poliovirus receptor (CD155). J. Immunol. 172, 3994-3998. doi: 10.4049/jimmunol.172.7.3994

Georgiev, H., Ravens, I., Papadogianni, G., and Bernhardt, G. (2018). Coming of age: CD96 emerges as modulator of immune responses. Front. Immunol. 9:1072. doi: 10.3389/fimmu.2018. 01072

Guihot, A., Marcelin, A. G., Massiani, M. A., Samri, A., Soulie, C., Autran, B., et al. (2018). Drastic decrease of the HIV reservoir in a patient treated with nivolumab for lung cancer. Ann. Oncol. 29, 517-518. doi: 10.1093/annonc/mdx696

Gupta, R. K., Abdul-Jawad, S., McCoy, L. E., Mok, H. P., Peppa, D., Salgado, M., et al. (2019). HIV-1 remission following CCR5Delta32/Delta32 haematopoietic stem-cell transplantation. Nature 568, 244-248. doi: 10.1038/s41586-019-1027-4

Holmes, V. M., Maluquer de Motes, C., Richards, P. T., Roldan, J., Bhargava, A. K., Orange, J. S., et al. (2019). Interaction between nectin-1 and the human natural killer cell receptor CD96. PLoS ONE 14:e0212443. doi: 10.1371/journal.pone.02 12443

Husain, B., Ramani, S. R., Chiang, E., Lehoux, I., Paduchuri, S., Arena, T. A., et al. (2019). A platform for extracellular interactome discovery identifies novel functional binding partners for the immune receptors 
B7-H3/CD276 and PVR/CD155. Mol. Cell Proteomics 18, 2310-2323. doi: 10.1074/mcp.TIR119.001433

Hutter, G., Nowak, D., Mossner, M., Ganepola, S., Mussig, A., Allers, K., et al. (2009). Long-term control of HIV by CCR5 Delta32/Delta32 stemcell transplantation. N. Engl. J. Med. 360, 692-698. doi: 10.1056/NEJMoa08 02905

Johnston, R. J., Comps-Agrar, L., Hackney, J., Yu, X., Huseni, M., Yang, Y., et al. (2014). The immunoreceptor TIGIT regulates antitumor and antiviral CD8(+) $\mathrm{T}$ cell effector function. Cancer Cell 26, 923-937. doi: 10.1016/j.ccell.2014.10.018

Karpinski, J., Hauber, I., Chemnitz, J., Schafer, C., Paszkowski-Rogacz, M., Chakraborty, D., et al. (2016). Directed evolution of a recombinase that excises the provirus of most HIV-1 primary isolates with high specificity. Nat. Biotechnol. 34, 401-409. doi: 10.1038/nbt.3467

Levin, S. D., Taft, D. W., Brandt, C. S., Bucher, C., Howard, E. D., Chadwick, E. M., et al. (2011). Vstm3 is a member of the CD28 family and an important modulator of T-cell function. Eur. J. Immunol. 41, 902-15. doi: $10.1002 /$ eji.201041136

Margolis, D. M., Garcia, J. V., Hazuda, D. J., and Haynes, B. F. (2016). Latency reversal and viral clearance to cure HIV-1. Science 353:aaf6517. doi: 10.1126/science.aaf6517

Martinet, L., and Smyth, M. J. (2015). Balancing natural killer cell activation through paired receptors. Nat. Rev. Immunol. 15, 243-254. doi: $10.1038 /$ nri3799

Matusali, G., Potesta, M., Santoni, A., Cerboni, C., and Doria, M. (2012). The human immunodeficiency virus type $1 \mathrm{Nef}$ and Vpu proteins downregulate the natural killer cell-activating ligand PVR. J. Virol. 86, 4496-4504. doi: 10.1128/JVI.05788-11

Mendelsohn, C. L., Wimmer, E., and Racaniello, V. R. (1989). Cellular receptor for poliovirus: molecular cloning, nucleotide sequence, and expression of a new member of the immunoglobulin superfamily. Cell 56, 855-865. doi: 10.1016/0092-867490690-9

Mousseau, G., Kessing, C. F., Fromentin, R., Trautmann, L., Chomont, N., and Valente, S. T. (2015). The tat inhibitor didehydro-cortistatin a prevents HIV-1 reactivation from latency. mBio 6:e00465. doi: $10.1128 / \mathrm{mBio} .00$ 465-15

Pauken, K. E., and Wherry, E. J. (2014). TIGIT and CD226: tipping the balance between costimulatory and coinhibitory molecules to augment the cancer immunotherapy toolkit. Cancer Cell 26, 785-787. doi: 10.1016/j.ccell.2014.11.016

Pende, D., Castriconi, R., Romagnani, P., Spaggiari, G. M., Marcenaro, S., Dondero, A., et al. (2006). Expression of the DNAM-1 ligands, Nectin-2 (CD112) and poliovirus receptor (CD155), on dendritic cells: relevance for natural killer-dendritic cell interaction. Blood 107, 2030-2036. doi: 10.1182/blood-2005-07-2696

Perreau, M., Savoye, A. L., De Crignis, E., Corpataux, J. M., Cubas, R., Haddad, E. K., et al. (2013). Follicular helper $\mathrm{T}$ cells serve as the major CD4 $\mathrm{T}$ cell compartment for HIV-1 infection, replication, and production. J. Exp. Med. 210, 143-156. doi: 10.1084/jem.20121932

Qu, X., Wang, P., Ding, D., Li, L., Wang, H., Ma, L., et al. (2013). Zinc-fingernucleases mediate specific and efficient excision of HIV-1 proviral DNA from infected and latently infected human T cells. Nucleic Acids Res. 41, 7771-7782. doi: 10.1093/nar/gkt571

Sanchez-Correa, B., Valhondo, I., Hassouneh, F., Lopez-Sejas, N., Pera, A., Bergua, J. M., et al. (2019). DNAM-1 and the TIGIT/PVRIG/TACTILE axis: novel immune checkpoints for Natural Killer cell-based cancer immunotherapy. Cancers 11:877. doi: 10.3390/cancers11060877

Shan, L., Deng, K., Shroff, N. S., Durand, C. M., Rabi, S. A., Yang, H. C., et al. (2012). Stimulation of HIV-1-specific cytolytic T lymphocytes facilitates elimination of latent viral reservoir after virus reactivation. Immunity 36, 491-501. doi: 10.1016/j.immuni.2012.01.014

Stanietsky, N., Simic, H., Arapovic, J., Toporik, A., Levy, O., Novik, A., et al. (2009). The interaction of TIGIT with PVR and PVRL2 inhibits human NK cell cytotoxicity. Proc. Natl. Acad. Sci. U. S. A. 106, 17858-17863. doi: $10.1073 /$ pnas.0903474106

Stengel, K. F., Harden-Bowles, K., Yu, X., Rouge, L., Yin, J., Comps-Agrar, L., et al. (2012). Structure of TIGIT immunoreceptor bound to poliovirus receptor reveals a cell-cell adhesion and signaling mechanism that requires cis-trans receptor clustering. Proc. Natl. Acad. Sci. U. S. A. 109, 5399-5404. doi: 10.1073/pnas.1120606109

Takai, Y., Miyoshi, J., Ikeda, W., and Ogita, H. (2008). Nectins and nectin-like molecules: roles in contact inhibition of cell movement and proliferation. Nat. Rev. Mol. Cell Biol. 9, 603-615. doi: 10.1038/nrm2457

Tauriainen, J., Scharf, L., Frederiksen, J., Naji, A., Ljunggren, H. G., Sonnerborg, A., et al. (2017). Perturbed CD8(+) T cell TIGIT/CD226/PVR axis despite early initiation of antiretroviral treatment in HIV infected individuals. Sci. Rep. 7:40354. doi: 10.1038/srep40354

Tremblay-McLean, A., Bruneau, J., Lebouche, B., Lisovsky, I., Song, R., and Bernard, N. F. (2017). Expression profiles of ligands for activating natural killer cell receptors on HIV infected and uninfected CD4(+) T cells. Viruses 9:295. doi: 10.3390/v9100295

Vassena, L., Giuliani, E., Matusali, G., Cohen, E. A., and Doria, M. (2013). The human immunodeficiency virus type $1 \mathrm{Vpr}$ protein upregulates PVR via activation of the ATR-mediated DNA damage response pathway. J. Gen. Virol. 94, 2664-2669. doi: 10.1099/vir.0.055541-0

Vendrame, E., Seiler, C., Ranganath, T., Zhao, N. Q., Vergara, R., Alary, M., et al. (2020). TIGIT is upregulated by HIV-1 infection and marks a highly functional adaptive and mature subset of natural killer cells. AIDS 34, 801-813. doi: 10.1097/QAD.0000000000002488

Vilches, C., Gardiner, C. M., and Parham, P. (2000a). Gene structure and promoter variation of expressed and nonexpressed variants of the KIR2DL5 gene. J. Immunol. 165, 6416-6421. doi: 10.4049/jimmunol.165.11.6416

Vilches, C., Rajalingam, R., Uhrberg, M., Gardiner, C. M., Young, N. T., and Parham, P. (2000b). KIR2DL5, a novel killer-cell receptor with a D0-D2 configuration of Ig-like domains. J. Immunol. 164, 5797-5804. doi: 10.4049/jimmunol.164.11.5797

Wang, F., Hou, H., Wu, S., Tang, Q., Liu, W., Huang, M., et al. (2015). TIGIT expression levels on human NK cells correlate with functional heterogeneity among healthy individuals. Eur. J. Immunol. 45, 2886-2897. doi: 10.1002/eji.201545480

Whelan, S., Ophir, E., Kotturi, M. F., Levy, O., Ganguly, S., Leung, L., et al. (2019). PVRIG and PVRL2 are induced in cancer and inhibit CD8(+) T-cell function. Cancer Immunol. Res. 7, 257-268. doi: 10.1158/2326-6066.CIR-18-0442

Wherry, E. J., Ha, S. J., Kaech, S. M., Haining, W. N., Sarkar, S., Kalia, V., et al. (2007). Molecular signature of CD8+ T cell exhaustion during chronic viral infection. Immunity 27:6. doi: 10.1016/j.immuni.2007. 09.006

Wherry, E. J., and Kurachi, M. (2015). Molecular and cellular insights into T cell exhaustion. Nat. Rev. Immunol. 15, 486-499. doi: 10.1038/nri3862

Wong, J. K., Hezareh, M., Gunthard, H. F., Havlir, D. V., Ignacio, C. C., Spina, C. A., et al. (1997). Recovery of replication-competent HIV despite prolonged suppression of plasma viremia. Science 278, 1291-1295. doi: $10.1126 /$ science.278.5341.1291

Wong, J. K., and Yukl, S. A. (2016). Tissue reservoirs of HIV. Curr. Opin. HIV AIDS 11, 362-370. doi: 10.1097/COH.0000000000000293

Wong, M. E., Jaworowski, A., and Hearps, A. C. (2019). The HIV reservoir in monocytes and macrophages. Front. Immunol. 10:1435. doi: 10.3389/fimmu.2019.01435

Wu, H., Chen, Y., Liu, H., Xu, L. L., Teuscher, P., Wang, S., et al. (2016). Follicular regulatory $\mathrm{T}$ cells repress cytokine production by follicular helper T cells and optimize IgG responses in mice. Eur. J. Immunol. 46, 1152-1161. doi: 10.1002/eji.201546094

Wykes, M. N., and Lewin, S. R. (2018). Immune checkpoint blockade in infectious diseases. Nat. Rev. Immunol. 18, 91-104. doi: 10.1038/nri.2017.112

Xu, F., Sunderland, A., Zhou, Y., Schulick, R. D., Edil, B. H., and Zhu, Y. (2017). Blockade of CD112R and TIGIT signaling sensitizes human natural killer cell functions. Cancer Immunol. Immunother. 66, 1367-1375. doi: 10.1007/s00262-017-2031-x

Yin, X., Liu, T., Wang, Z., Ma, M., Lei, J., Zhang, Z., et al. (2018). Expression of the inhibitory receptor TIGIT is up-regulated specifically on NK cells with CD226 activating receptor from HIV-infected individuals. Front. Immunol. 9:2341. doi: 10.3389/fimmu.2018.02341

Yu, X., Harden, K., Gonzalez, L. C., Francesco, M., Chiang, E., Irving, B., et al. (2009). The surface protein TIGIT suppresses T cell activation by promoting the generation of mature immunoregulatory dendritic cells. Nat. Immunol. 10, 48-57. doi: 10.1038/ni.1674 
Zhang, Q., Bi, J., Zheng, X., Chen, Y., Wang, H., Wu, W., et al. (2018). Blockade of the checkpoint receptor TIGIT prevents NK cell exhaustion and elicits potent anti-tumor immunity. Nat. Immunol. 19, 723-732. doi: 10.1038/s41590-018-0132-0

Zhu, W., Lei, R., Le Duff, Y., Li, J., Guo, F., Wainberg, M. A., et al. (2015). The CRISPR/Cas9 system inactivates latent HIV-1 proviral DNA. Retrovirology 12:22. doi: 10.1186/s12977-015-0150-Z

Zhu, Y., Paniccia, A., Schulick, A. C., Chen, W., Koenig, M. R., Byers, J. T., et al. (2016). Identification of CD112R as a novel checkpoint for human T cells. J. Exp. Med. 213, 167-176. doi: 10.1084/jem.20150785
Conflict of Interest: The authors declare that the research was conducted in the absence of any commercial or financial relationships that could be construed as a potential conflict of interest.

Copyright (C) 2020 Holder and Grant. This is an open-access article distributed under the terms of the Creative Commons Attribution License (CC BY). The use, distribution or reproduction in other forums is permitted, provided the original author(s) and the copyright owner(s) are credited and that the original publication in this journal is cited, in accordance with accepted academic practice. No use, distribution or reproduction is permitted which does not comply with these terms. 